ISSN: 2521-2893 (Print)

ISSN: 2521-2907 (Online)

CODEN: ESPADC

\title{
STUDY OF SPATIAL AND TEMPORAL VARIABILITY OF ARSENIC IN GROUNDWATER DUE TO DRAIN BY USING GIS
}

\author{
Ch. Arslan 1*, Asma Sattar' ${ }^{1}$, Do Minh Cuong ${ }^{2}$, Faizan ul Haq Khan ${ }^{1}$, Abdul Nasir ${ }^{1}$, Zia Bakhat ${ }^{3}$, Fariha Ilyas ${ }^{4}$ \\ ${ }^{1}$ Department of Structures and Environmental Engineering, University of Agriculture, Faisalabad \\ ${ }^{2}$ Hue University of Agriculture and Forestry, Hue University, Hue city, Vietnam. \\ ${ }^{3}$ Institute of Food Science and Technology, University of Agriculture, Faisalabad \\ ${ }^{4}$ College of Soil Science, Bahaudin Zikria University, Multan \\ *Corresponding Author Email: arslanakrampk@hotmail.com
}

This is an open access article distributed under the Creative Commons Attribution License, which permits unrestricted use, distribution, and reproduction in any medium, provided the original work is properly cited.

\section{ARTICLE DETAILS}

\section{Article History:}

Received 26 June 2018

Accepted 2 July 2018

Available online 1 August 2018

\section{ABSTRACT}

Industrial activity is one of the major reason of groundwater contamination. Arsenic is one, which is responsible for the contamination of the groundwater. Its testing in groundwater is considered as an important activity due to its serious effects on human health. Arsenic problem in Pakistan has been identified recently as a result of field testing. In Faisalabad, arsenic has been found in groundwater within permissible limit. But due to increasing industrial activities the concentration of arsenic is increasing day by day. Drain passing through the city is one of the sources of arsenic in groundwater. The research work was conducted at Syedabbad, Faisalabad. Samples were taken from the selected drain portion and from the groundwater by the help of water pumps. The sampling points were drawn on GIS map by the help of GPS receiver to study the spatial variability of arsenic contamination The results shows that there $10109.9 \mathrm{mg}$ per second intake of arsenic due to drain. Results show that there is no temporal variability of arsenic within the research period but they have spatial variability.

\section{KEYWORDS}

Arsenic, groundwater, permissible limit, GPS receiver, sampling points.

\section{INTRODUCTION}

Groundwater is an important source of drinking water and its quality is subjected to threat due to manmade activities like industrial development as mandatory to cop the demands of growing population which is one of the major the focal reason for groundwater contamination especially in industrial cities like Faisalabad.

Pahatang and Madhhuana are the two main drains passing through the center of the Faisalabad city having most of its portion unlined and utilized for the disposal of industrial wastewater [1-12]. These industrial effluents mostly consist of untreated wastewater carrying hazardous substances which were continuously leaching down to groundwater and causing its contamination $[13,14]$. Arsenic is one of them which when soluble in water became odourless, colourless and tasteless and it can cause many health disorders like skin diseases to the human being.

GIS is one of the most powerful tools to visualize groundwater contamination as it consists of different geo statistics tools combined with advanced overlapping technologies and map development options which helps to study the spatial variability of groundwater contaminants.

\section{MATERIALS AND METHODS}

\subsection{Description of Study Area}

For this study, some area of Syedabbad located near the University of Agriculture Faisalabad was selected where many cases of skin diseases were observed in pre-research survey representing the possible arsenic contamination and unlined portion of drain was passing through the area having some portion of drain covered for safety reason as some cases were reported where children fall in the drain [2,15-17]. It was also observed that wastewater in that selected area, wastewater added in the drain was domestic though it carried industrial waste previously.

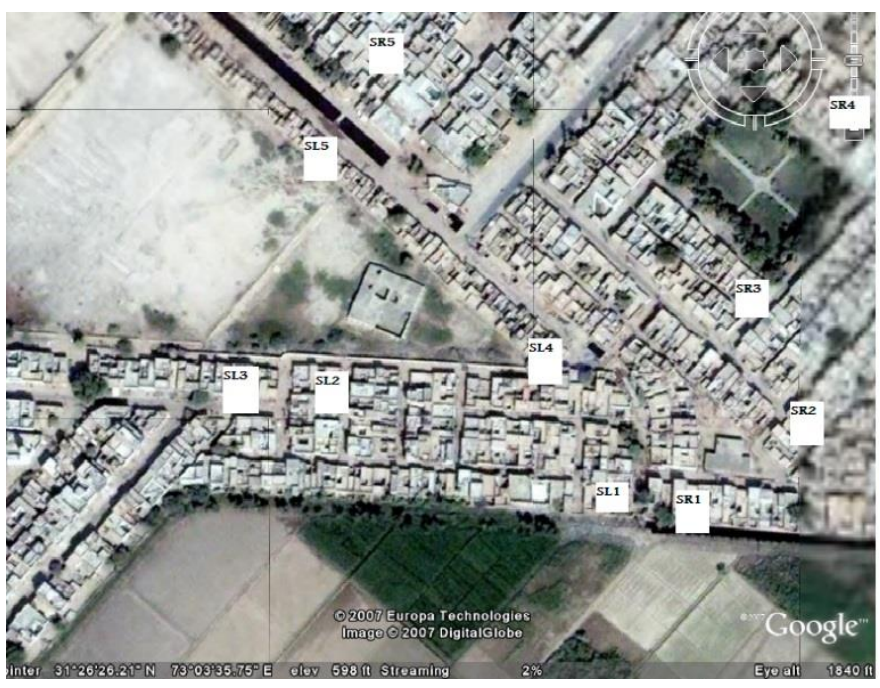

Figure 1: Arial photograph of the area with sampling points

\subsection{Wastewater and Groundwater Sampling}

Samples were taken at the start (inlet) and end (outlet) of selected portion to evaluate the amount of arsenic leached through that portion. At inlet portion, nine samples were taken from corners and center at three different depths and mix together to get one representing sample of 500 
mL PVC bottle which was sealed properly. Same practice was repeated to get the sample at the end of selected drain portion.

For groundwater sampling, ten houses were randomly selected having newly installed water pumps to maintain same groundwater sampling depth in which five were on left and five were on right side of selected portion of drain [18-20]. Five repetitions were made each after fifteen days to evaluate temporal variability of arsenic. In order to take sample from the groundwater, pump was run for almost ten minutes to get freshwater supply from its direct connection then $500 \mathrm{~mL}$ sample was collected in PVC bottle and sealed it after proper sample labeling.

\subsection{Wastewater Flow Measurement}

Flow of drain depends upon two parameters; velocity of waste water and cross sectional area of the channel [21]. Velocity of the drain was measured by the help of the float method and the cross section of the drain was calculated by mid ordinate rule at five different points [3].

\subsection{Data Analysis}

Position data was collected through Explorsist 210 GPS. This data was imported into geographic information system (GIS) software, allowing spatial aspects to be analyzed with other information to create a map far more complete understanding of a particular situation than might be possible through conventional means [22-27]. For this purpose ArcGIS v9.0 version was used. For arsenic determination Mercury/Hydride System HS55 atomic adsorption spectrometer was used and standard procedure was adopted for testing.

\section{RESULTS AND DISCUSSION}

\subsection{Temporal variation in Arsenic intake from the drain}

The research was started on April 2007 and ended in June 2007. The average cross section of the drain was found to be $8.95 \mathrm{~m}^{2}$. The average wastewater flow varied from $2.670 \mathrm{~m}^{3} / \mathrm{s}$ to $2.854 \mathrm{~m}^{3} / \mathrm{s}$ as shown in Figure 2. The average arsenic intake in the selected area was from $0.426 \mathrm{mg} / \mathrm{s}$ to $0.714 \mathrm{mg} / \mathrm{s}$ as shown in figure 3. It was observed that peak values of arsenic intake correspond to the peak value of flow during the research period. On the other end, the variation trend in both was also similar.
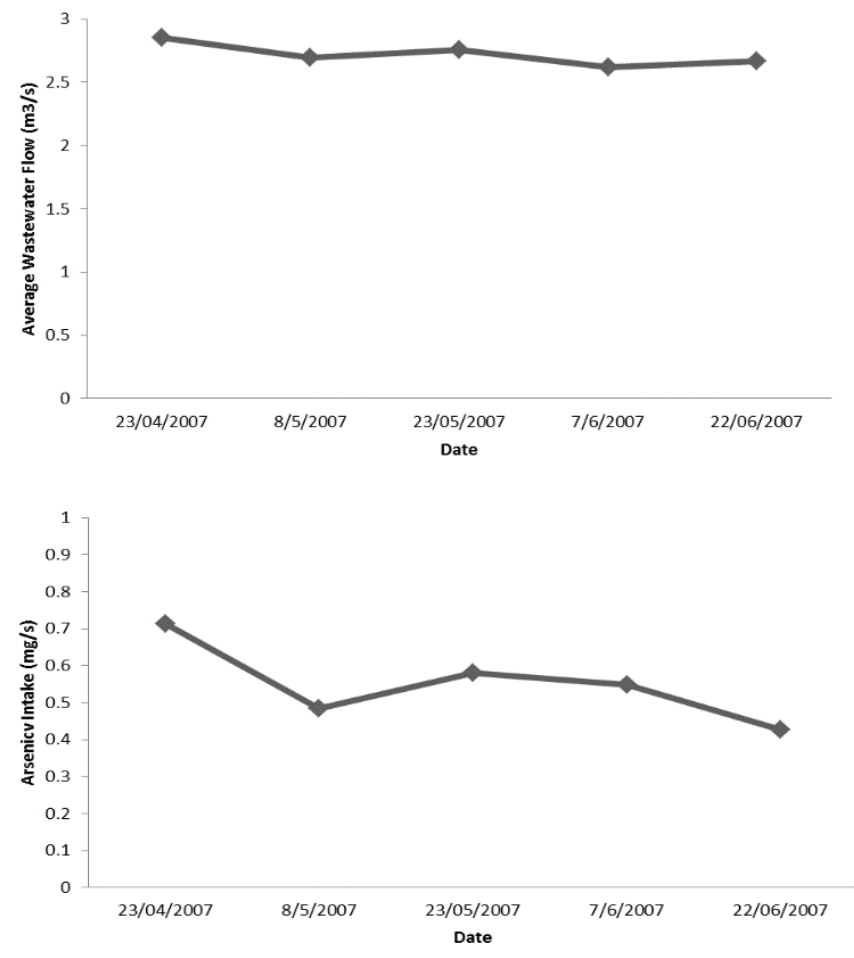

Figure 2: Arsenic intake from drain

\subsection{Spatial and temporal variation of Arsenic in Groundwater}

There was no temporal variation found in arsenic level of groundwater during the study period. Spatial variation of the arsenic was represented by the help of GIS map in figure 4. Concentrations were represented by the diameter of the circle and points were located by the help of their coordinates taken by Explorsist 210GPS receiver.

It was observed that points SL1 and SR1 were equidistance from the drain and have similar population density and have same arsenic concentration of $0.001 \mathrm{mg} / \mathrm{L}$ whereas points SL2, SL3, SL5 and SR3 have same arsenic level of 0.002 although they are little far from drain as compare to SL1 and SR1 but at these points the population density is more which cause more pumping which affect the arsenic concentration [4]. SL4, SR2 and SR4 have same arsenic concentration of $0.003 \mathrm{mg} / \mathrm{L}$ but points SR2 and SR4 were more populated as compare to SL4 still they all have the same concentration. SL4 was located at turning of drain due to which it has higher level as compare to its population. SR5 have the maximum concentration due to high population density and it was near to the drain as compare to SL4, SR2 and SR4.

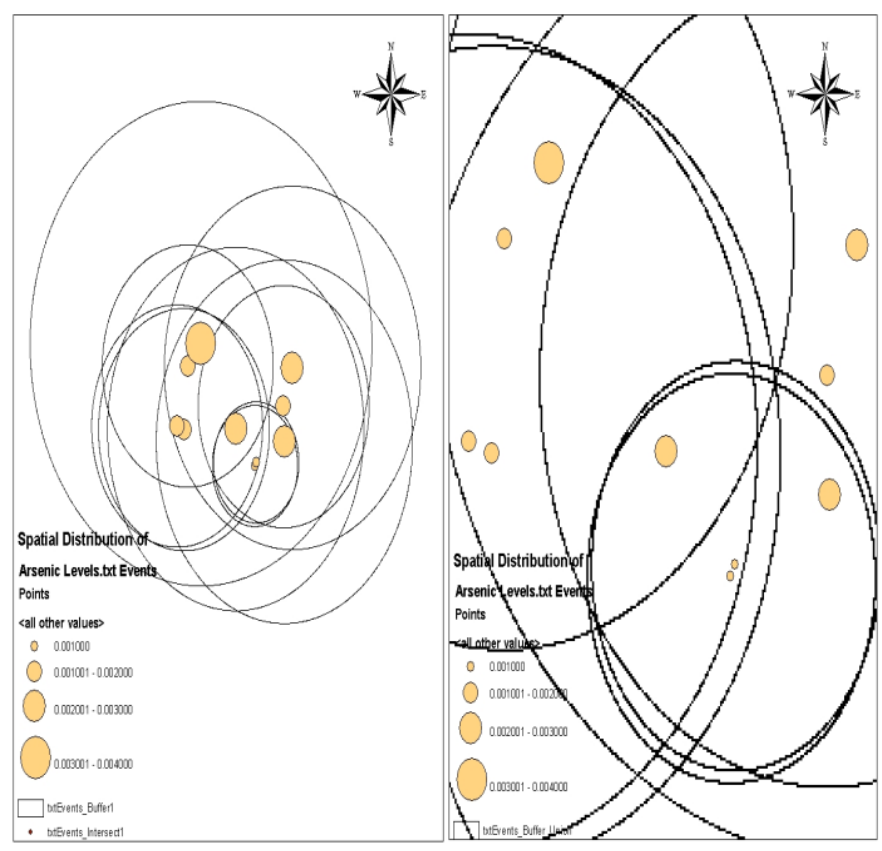

Figure 3: Spatial variation of Arsenic; Point influence (left), group influence (right)

\section{CONCLUSION}

The study was conducted on spatial and temporal variation of arsenic due to drain and it was observed that there was no temporal variability of arsenic concentration in groundwater but there was temporal variability of arsenic in the drain. There was spatial variability in arsenic on both sides of drain indicating the effect of drain. In the study area arsenic concentration lied in permissible region e.g. less than $0.01 \mathrm{mg} / \mathrm{l}$, which indicates that the skin diseases were due to unhygienic life style.

\section{REFERENCES}

[1] Khurshid, A., Ali, W. 1999. Evaluation of water quality of rivers in Pakistan. National Workshop on Water resources Achievements and Issues in 20th Century and Challenges for the next Millennium. Proceeding of the Pakistan Council of Research in water Resources. June 28-30, 406416.

[2] Shrestha, B.R., Whitney, J.W., Shrestha, K.B. 2004. The state of arsenic in Nepal 2003. National Arsenic Steering Committee (Nepal), Environmental and Public Health Organization, Nepal.

[3] Kanetkar, T.P., Kulkarni, S.V. 1995. Surveying and Leveling Part 1. Pune Vidharthi Griha Prakashan, pp. 312-313.

[4] Acharyya, S.K., Acharyya, A.F., Subhrangsu, K. 2007. Groundwater arsenic contamination affecting different geologic domains in India - a review: influence of geological setting, fluvial geomorphology and quaternary stratigraphy. Journal of Environmental Science and Health 
Part A-Toxic/Hazardous Substances \& Environmental Engineering, 42 (12), 1795-1805

[5] Abernathy, C.0. 1993. Draft drinking water criteria document on arsenic. USEPA Science Advisory Board Report, Washington, USA.

[6] Acharyya, S.K. 1997. Arsenic in groundwater - geological overview. Consultation on arsenic in drinking water and resulting arsenic toxicity in India and Bangladesh, WHO, New Delhi, 25 (4), 49-54.

[7] Ahmed, K., Ali, W. 2000. Evaluation of Ravi river water quality. Drainage Research Centre (PCRWR). Tandojam, Pakistan, Journal of Drainage and Water Management, 4 (1-2),

[8] Ahmed, R. 1998. Impact of environmental pollution in Rawalpindi and Islamabad. 24th WEDC Conference, Islamabad, Pakistan.

[9] Berry, J.K. 2003. Map analysis: procedures and applications in GIS modeling. BASIS Press, Fort Collins, Colorado. pp:55-63.

[10] Burrough, P.A., McDonnell, R.A. 1998. Principles of Geographical Information Systems. Oxford University Press. pp:1.

[11] Chung, J.S., Haque, R., Mazumder, D.N.G. 2006. Blood concentration of methionine, selenium, beta-carotene and other micronutrients in a case control study of arsenic induced skin lesions in West Bangal, India. Environmental Research, Orlando, USA, 101 (2), 230-237.

[12] Guillot, S., Charlet, L., Guillot, A.F., Charlet, S. 2007. Bengal arsenic, an archive of Himalaya orogeny and paleohydrology. Journal of Environmental Science and Health Part A-Toxic/Hazardous Substances \& Environmental Engineering, 42 (12), 1785-1794.

[13] Hassan, M.M., Atkins, P.J., Peter, J. 2007. Arsenic risk mapping in Bangladesh: a simulation technique of cokriging estimation from regional count data. Journal of Environmental Science and Health Part AToxic/Hazardous Substances \& Environmental Engineering, 42 (12), 1933-1944.

[14] Hussam, A., Hussam, A.F., Munir, A. 2007. A simple and effective arsenic filter based on composite iron matrix: Development and deployment studies for groundwater of Bangladesh. Journal of Environmental Science and Health Part A-Toxic/Hazardous Substances \& Environmental Engineering, 42 (12), 1869-1878.

[15] João, E., Fonseca, A. 1996. The role of GIS in improving environmental assessment effectiveness: theory versus practice. An Impact Assessment Report. International Association for Impact Assessment, 14 (7), 371-385.

[16] Kahlown, M.A., Tahir, M.A. 2001. Quality analysis of bottled mineral water. Pakistan Council of Research in Water Resources, Islamabad (Unpublished). Karachi. 24th WEDC Conference, Sanitation and Water for All.
Islamabad, Pakistan.

[17] Khurshid, A., Ali, W. 1999. Evaluation of water quality of rivers in Pakistan. National Workshop on Water resources Achievements and Issues in 20th Century and Challenges for the next Millennium. Proceeding of the Pakistan Council of Research in water Resources, 28-30, 406-416.

[18] Mashiatullah, A., Qureshi, R.M., Qureshi, N.A., Ahmed, E. 2002. Physiochemical and biological quality of Potable Groundwater in Karachi, Seminar on Strategies to Address the Present and Future Water Quality Issues. March 6-7. Pakistan Council of Research in Water Resources. Islamabad.

[19] Shin, C.J., Wuing, L.C., Hung, L.K., Mei, H.F., Wei, W.S. 2006. Spatital analysis of potential carcinogenic risks associated with ingesting Arsenic in agricultural tilapia in blackfoot dises hyperendemic areas, Environmental Science \& Technology (A special report), Department of Bioenvironmental Systems Engineering, National Taiwan University, Taipei, Taiwan, 40 (5), 1707-1713.

[20] Shrestha, B.R., Whitney, J.W., Shrestha, K.B. 2004. The state of arsenic in Nepal 2003. National Arsenic Steering Committee (Nepal), Environmental and Public Health Organization, Nepal.

[21] Sial, J.K., Mehmood, S. 1999. Water pollution from agriculture and industry.

[22] Tahir, M.A. 2000. Arsenic in ground water of Attock and Rawalpindi Districts. Joint Venture PCRWR \& UNICEF, Islamabad (Un-published).

[23] Tong, N.T. 2002. Arsenic pollution in groundwater in the Red River Delta. ESCAP-IWMI Seminar on Environmental and Public Health Risks Due to Contamination of Soils, Crops, Surface and Groundwater from Urban, Industrial and Natural Sources in South East Asia, 10-12 December 2002, Hanoi, Vietnam.

[24] Vijay, R., Panchbhai, N., Gupta, A. 2007. Spatio-temporal analysis of groundwater recharges and mound dynamics in an unconfined aquifer: a GIS-based approach. Hydrological Processes, 21 (20), 2760-2764.

[25] Vijith, H., Satheesh, R. 2007. Geographical Information System based assessment of spatiotemporal characteristics of groundwater quality of upland sub-watersheds of Meenachil River, parts of Western Ghats, Kottayam District, Kerala, India. Environmental Geology, 53 (1), 1-9.

[26] Watanabe, C., Matsui, T., Inaoka, T., Ohtsuka, R., Bokul, R. 2007. Dermatological and nutritional/growth effects among children living in arsenic-contaminated communities in rural Bangladesh. Journal of Environmental Science and Health Part A-Toxic/Hazardous Substances \& Environmental Engineering, 42 (12), 1835-1841.

[27] Wikipedia. 2008. URL http:// en.wikipedia.org/wik/Faisalabad. 